\title{
An Efficient Method for Earth Resistance Reduction Using the Dead Sea Water
}

\author{
Yousif El-Tous, Salim A. Alkhawaldeh \\ Department of Electrical Engineering, Faculty of Engineering Technology, Al-Balqa Applied University, Amman, \\ Jordan \\ Email: yousifeltous@yahoo.com, skhawaldeh@yahoo.com
}

Received 26 January 2014; revised 26 February 2014; accepted 5 March 2014

Copyright $@ 2014$ by authors and Scientific Research Publishing Inc.

This work is licensed under the Creative Commons Attribution International License (CC BY). http://creativecommons.org/licenses/by/4.0/

(c) (i) Open Access

\section{Abstract}

To protect humans, devices and maintain high reliability of electrical equipments, efficient earthing system has to be provided for residential and commercial buildings. The use of chemical elements around the electrode of earthing systems reduces the earth resistance which improves the efficiency of these systems. However, the use of these elements can't achieve very small earth resistance especially in the case of dry clay. In addition, they are expensive and not available all the time. This paper presents a method that treats the soil with adding the Dead Sea water instead of the chemical elements to further reduce the earth resistance and to avoid the expenses of these elements. In our approach, the Dead Sea water is added to a hole around the electrode with a distance not exceeding $10 \mathrm{~cm}$ to avoid the corrosion layer on the electrode. Practical measurements are demonstrated to show the efficiency of the proposed approach.

\section{Keywords}

\section{Grounding System, Earth Resistance, Soil Treatment}

\section{Introduction}

As a result of the design errors, operational factors, air or insulation breakdowns, electrical shock accidents usually happen. Due to a large number of these accidents, earthing systems have taken a lot of research attention [1]. Good earthing systems reduce the results of damages and maintain high reliability of devices caused by lightning or fault currents [2] [3]. To reach good grounding system, the resistance in ohm between the grounding electrode and the earth has to be relatively small. As it decreases, the grounding connection improves. This resistance refers to earth resistance. The accepted value of the earth resistance differs from applications to applications. Some of them accept earth resistance of $25 \mathrm{ohm}$ or less whereas others accept it of $3 \mathrm{ohm}$ or less. 
In the case of earth fault conditions, the low earth resistance enables the protection system to isolate the power source and makes the earth potential rise (EPR) less dangerous to humans [4] [5]. To improve the personal safety, the equipment protection and to maintain the continuity of the power supply, buildings have to be provided by such systems [6] [7]. These systems provide alternative and low resistance path for leakage or faulty current to flow [8]. It protects buildings from the effect of lightning and reduces the electromagnetic disturbances. Also, it is used as a reference voltage in case of measurements. Recently, a number of earthing systems have been proposed to improve the grounding connection efficiency [9]-[11].

To reduce the earth resistance, chemical elements are added to the soil around the electrode [12]. However, these elements are expensive and sometimes can't ensure good grounding connection [13]. In this paper, we propose an earthing system that uses the Dead Sea water instead of the chemical elements. Experimental results show that significant reduction in the earth resistance has been obtained compared to the case without soil treatment.

\section{Earth Resistance without Soil Treatment}

Measuring the earth resistance is very important to ensure that it is equal or les the design required value of the building. There are many methods for measuring the earth resistance such as the 2-pole method, 3-pole-fall-ofpotential method, and 4-pole method. In this section, we introduce practical experiments for measuring the earth resistance in the field of National Electricity Company (NEPCO), Jordan. In these experiments, devices such as Hammer, Axe, Shovel, Electrode and Wires were used.

C.A. 6423 Digital Earth Tester shown in Figure 1 was used to measure the earth resistance. The features of this tester are as follows:

- 2-pole \& 3-pole methods.

- Measurement range 0.01 to $2000 \Omega$.

- Measurement frequency $128 \mathrm{~Hz}$.

- Confirmation of the measurement by self-diagnosis.

- 3 fault presence indicators to validate measurement.

- Colour-coded terminals for connecting rods.

- Protection by HRC fuse.

- Leak proof on-site casing.

- Large galvanometer.

In our experiments, the 3-pole-fall-of-potential method was used to measure the dissipation capability of a single ground electrode, ground grids, foundation grounds and other grounding systems. As shown in Figure 2, an electrode of $120 \mathrm{~cm}$ length, diameter of $0.8 \mathrm{~cm}$, steel-galvanized copper was used to connect devices with the earth. Also, two assistant electrodes $\mathrm{C}$ and $\mathrm{P}$ are used. These assistant electrodes were put at suitable distance from earth electrode $\mathrm{E}$ which is needed to measure the earth resistance. The assistant electrodes length was of 30 $\mathrm{cm}$ and the distance between $\mathrm{E}$ and $\mathrm{P}$ was at least 30 meters. Note that the soil of our experiment is a dry clay. The actual value of the ground electrode under the test can be obtained as V/I.

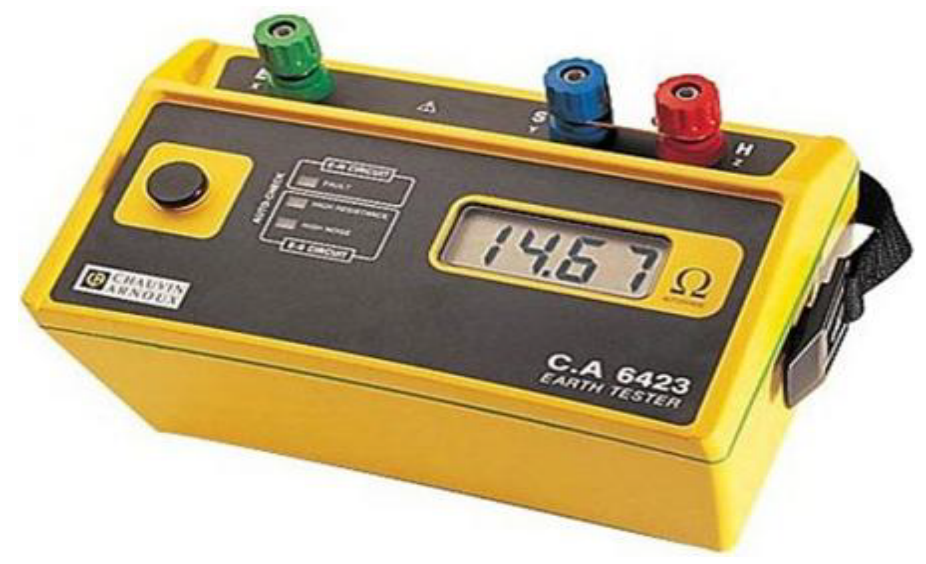

Figure 1. C.A. 6423 Digital Earth Tester. 


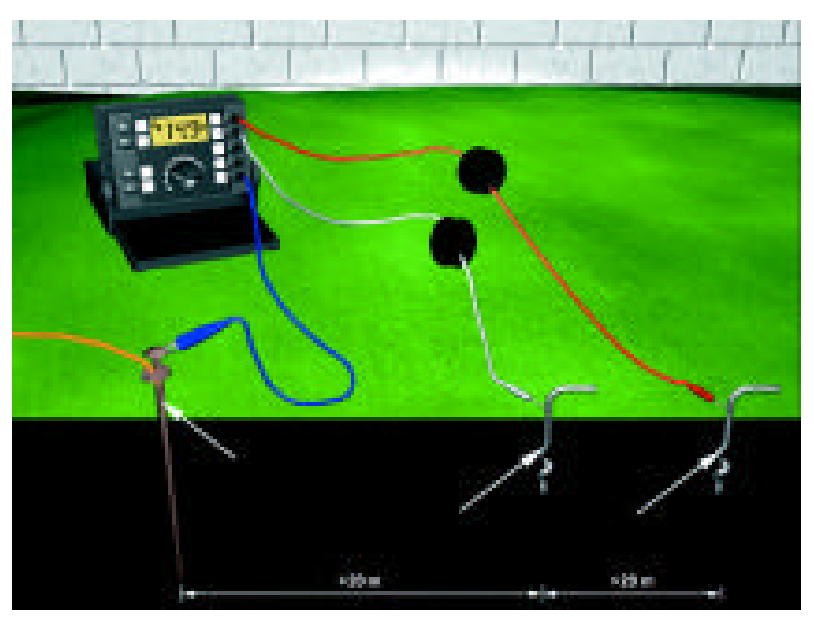

Figure 2. Three-pole-testing method.

\subsection{Earth Resistance Based on Single Rode}

\subsubsection{Theoretical Calculations}

We take the following values for the used components:

- Soil resistivity $(\rho=38.4-\mathrm{ohm} \cdot \mathrm{m})$.

- Electrode length $(L=1.2 \mathrm{~m})$.

- Electrode diameter $(d=0.8 \mathrm{~cm})$.

- Distance between two electrodes $(s=2.4 \mathrm{~m})$.

To calculate the earth resistance of a system consists of single electrode, the following equation is used

$$
R=\frac{\rho}{2 L}\left\{\ln \left(\frac{4 L}{d / 2}\right)-1\right\}
$$

where $\rho$ is the soil resistivity in $(\Omega \cdot \mathrm{m}), L$ is the length of electrode in $(\mathrm{m})$ and $d$ is the diameter of electrode in $(\mathrm{cm})$. The calculated value of the resistance can be obtained as

$$
R=\frac{38.4}{2 \times 1.2}\left\{\ln \left(4 \times \frac{1.2}{0.4}\right)-1\right\}=23.8 \Omega
$$

\subsubsection{Experimental Results}

Initially, we inserted single electrode $\mathrm{E}$ in the ground at a several depths $(40,80,100 \mathrm{~cm})$. Let the distance between electrodes $\mathrm{E}$ and $\mathrm{P}=\mathrm{D}_{\mathrm{EP}}$ and the distance between electrodes $\mathrm{C}$ and $\mathrm{E}=\mathrm{D}_{\mathrm{CE}}$. The measurements of the ground resistance were taken at $\mathrm{D}_{\mathrm{CE}}=52 \%, 62 \%$, and $72 \%$ of $\mathrm{D}_{\mathrm{EP}}$ as shown in Tables 1-3.

The relative error between the theoretical and the practical values for single electrode is given as

$$
\begin{gathered}
\text { Error }=E=\left|\frac{\text { theoretical value }- \text { measure value }}{\text { theoretical value }}\right| \times 100 \% \\
E=\left|\frac{23.8-20.4}{23.8}\right| \times 100 \%=14.3 \%
\end{gathered}
$$

\subsection{Earth Resistance Based on Parallel Two Rods}

\subsubsection{Theoretical Calculations}

We calculate the earth resistance of a system consists of two electrodes in parallel as follows:

In the beginning, the earth resistance for a single electrode is given as

$$
R v=\frac{\rho}{L}=\frac{38.4}{1.2}=32 \Omega
$$


Table 1. Measured earth resistance at a distance $\mathrm{D}_{\mathrm{CE}}=52 \%$ of $\mathrm{D}_{\mathrm{EP}}$.

\begin{tabular}{cc}
\hline Depth of electrode $(\mathrm{m})$ & Measured earth resistance $(\Omega)$ \\
\hline 0.4 & 43.5 \\
0.8 & 28.1 \\
1 & 20.3 \\
\hline
\end{tabular}

\begin{tabular}{|cc|}
\hline Table 2. Measured earth resistance at a distance $\mathrm{D}_{\mathrm{CE}}=62 \%$ of $\mathrm{D}_{\mathrm{EP} .}$. \\
\hline Depth of electrode $(\mathrm{m})$ & Measured earth resistance $(\Omega)$ \\
\hline 0.4 & 41 \\
0.8 & 28.3 \\
1 & 20.4 \\
\hline
\end{tabular}

Table 3. Measured earth resistance at a distance $\mathrm{D}_{\mathrm{CE}}=72 \%$ of $\mathrm{D}_{\mathrm{EP}}$.

\begin{tabular}{cc}
\hline Depth of electrode $(\mathrm{m})$ & Measured earth resistance $(\Omega)$ \\
\hline 0.4 & 44 \\
0.8 & 28.5 \\
1 & 21.7 \\
\hline
\end{tabular}

$$
\frac{s}{L}=\frac{2.4}{1.2}=2
$$

where $s$ is the distance between the electrodes and $L$ is the length of electrode.

When $S / L=2$ and the number of electrodes $N=2$, the correction factor value $\eta=0.94$ and the calculated total earth resistance in the case of two electrodes in parallel is obtained as

$$
R \text { tot }=\frac{R v}{\eta \times N}=\frac{32}{0.94 \times 2}=17.02 \Omega
$$

\subsubsection{Experimental Results}

In this section, we insert two parallel identical electrodes having the same properties at a depth of $1 \mathrm{~m}$. The two parallel electrodes are separated by $2.4 \mathrm{~m}$. The measurements of the ground resistance were taken at $\mathrm{D}_{\mathrm{CE}}=52 \%$, $62 \%$, and $72 \%$ of $\mathrm{D}_{\mathrm{EP}}$ as shown in Table 4 .

It can be seen that the reduction cased by adding a second rod is small. Also, it is worthy of noting that in the case of single or 2 parallel electrodes, the earth resistance is relatively high. This is due to the fact that the soil used in the experiment is dry clay which has large resistance. However, in some environments, it is difficult to insert the electrode to deep distance. This is a big problem of the earthing systems.

The relative error between the theoretical and the practical values for two electrodes in parallel is given as

$$
\begin{gathered}
\text { Error }=E=\left|\frac{\text { theoretical value }- \text { measure value }}{\text { theoretical value }}\right| \times 100 \% \\
E=\left|\frac{17.02-19.4}{17.02}\right| \times 100 \%=E=13.9 \%
\end{gathered}
$$

\section{Proposed Method for Soil Treatment Using the Dead Sea Water}

As demonstrated in Section 3, the measured earth resistance is relatively high. To reduce this resistance, the soil 
Table 4. Measured earth resistance at a depth of electrode $=1 \mathrm{~m}$.

\begin{tabular}{ccc}
\hline Distance $\mathrm{D}_{\mathrm{CE}}$ & Depth of electrode $(\mathrm{m})$ & Measured earth resistance $(\Omega)$ \\
\hline $52 \%$ of $\mathrm{D}_{\mathrm{EP} .}$ & 1 & 19.6 \\
$62 \%$ of $\mathrm{D}_{\mathrm{EP} .}$ & 1 & 19.4 \\
$72 \%$ of $\mathrm{D}_{\mathrm{EP} .}$ & 1 & 19.6 \\
\hline
\end{tabular}

can be treated chemically by adding some elements such as magnesium, sulphate salt, copper sulphate, coal, salt, sodium chloride, iron filings and so on. However, these elements are expensive and the improvement obtained by addition of these elements is not significant especially when the depth of electrode is small. Therefore, in this paper, we propose a method that uses the Dead Sea water instead of these elements. Fortunately, the Dead Sea water contains all of these elements and many others and it is available any time. The concentration of the minerals, organic substances and water in the Dead Sea is equal to $62.4 \%, 22.4 \%$ and $15.2 \%$, respectively. Table 5 shows the concentration of a number of elements in the Dead Sea.

In our approach, the Dead Sea water is added to a hole around the electrode with a distance not exceeding 10 $\mathrm{cm}$ until a level of $30 \mathrm{~cm}$ from the surface of the ground as shown in Figure 3. In this figure, the soil mixed with Dead Sea water is shown as a dark colour ring. This is to avoid the direct contact between the rod and the materials of the Dead Sea water which prevent the composition of corrosion layer.

To further reduce the earth resistance, we add the Dead Sea water with coal and iron filings as shown in Figure 4. The coal and iron filings are not expensive and available. In some cases, the reasons of reducing the amount of water salt added in the hole are the floods and rain. So, the Dead Sea water has to be renewed every two years according to the porosity of the ground and the amount of rain.

Our approach can be used for the ring systems where large number of electrodes are inserted in deep holes. During the installation of these holes, some Dead Sea water is added to reduce the earth resistance. Also, it is recommended to put a plastic pipe contains small holes at the bottom around the electrode to protect it from corrosion.

\section{Experimental Results and Discussions}

Table 6 presents the measured values of the earth resistance with addition of 5 litters of the Dead Sea water at electrode depth of $1 \mathrm{~m}$. As expected, significant reduction in the earth resistance has been obtained compared to the case without soil treatment. Also, it is shown that the adding of the second rod decreases the earth resistance to approximately $77 \%$ of that in the case of single rod. This is a big advantage of our proposed method compared to the method that doesn't use the soil treatment.

To further reduce the earth resistance, we add the Dead Sea water with Coal and iron-filings which are not expensive and available. The earth resistance measurements in this case are shown in Table 7. It can be noted that further significant reduction of the earth resistance is achieved.

As an extra example of our approach, we carried out a simple experiment in our college, Faculty of Engineering, Jordan, which is far $25 \mathrm{~km}$ from the NEPCO. In this experiment, we measured the resistance of inserted electrode used as a ground of a specific diesel generator. The length of this electrode is $1.2 \mathrm{~m}$ and has steel copper clad. The resistance of that electrode was $2.7 \mathrm{ohm}$. After we added some of the Dead Sea water to the soil around that electrode, the earth resistance was measured of $0.5 \mathrm{ohm}$. This verifies that the addition of the Dead Sea water significantly decreases the earth resistance which leads to very efficient grounding system.

\section{Conclusion}

In this paper, we proposed a method for soil treatment using the Dead Sea water which is not expensive and available all the time. The Dead Sea water has many elements used to decrease the earth resistance. Experimental results showed that significant reduction in the earth resistance is achieved in the case of soil treatment using the Dead Sea water compared to the case without soil treatment. Further reduction of the earth resistance was obtained by adding the Dead Sea water with cool and iron filings which are not expensive and available all the time. Also, it was noted that when a second rod is added, the earth resistance significantly decreases in the case 


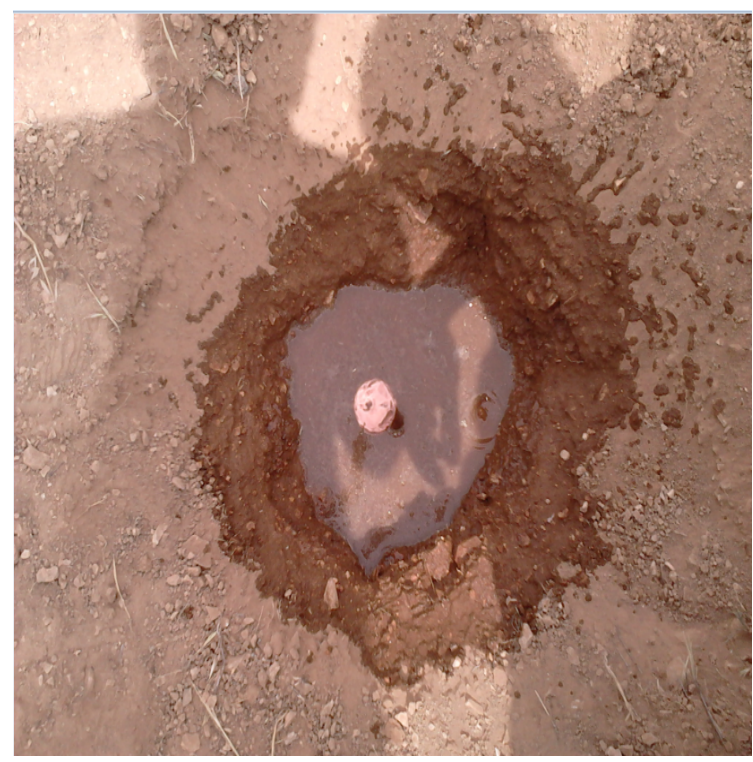

Figure 3. Addition of the Dead Sea water to the hole of grounding system.

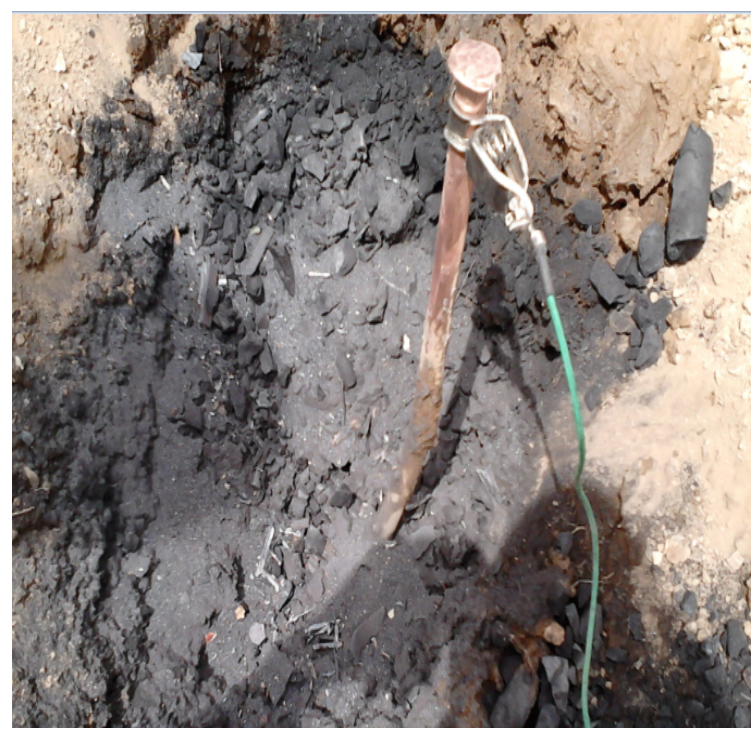

Figure 4. Addition of the Dead Sea water with Coal and iron-filings tothe hole of grounding system.

Table 5. Concentration of a number of elements in the Dead Sea.

\begin{tabular}{cc}
\hline Element & Concentration $\mathbf{~ m g} / \mathbf{L}$ \\
\hline Chlorine & 224.9 \\
Magnesium & 44.0 \\
Sodium & 40.1 \\
Calcium & 17.2 \\
Potassium & 7.65 \\
Bromine & 5.3 \\
\hline
\end{tabular}


Table 6. The measured earth resistance with addition of 5 litters of the Dead Sea water at electrode depth of $1 \mathrm{~m}$.

\begin{tabular}{ccc}
\hline & \multicolumn{2}{c}{ Measured earth resistance $(\Omega)$} \\
\cline { 2 - 3 } Distance $\mathrm{D}_{\mathrm{CE}}$ & Single Rod & Double Rods \\
\hline $52 \%$ of $\mathrm{D}_{\mathrm{EP} .}$ & 13.36 & 10.38 \\
$62 \%$ of $\mathrm{D}_{\mathrm{EP} .}$ & 13.46 & 10.48 \\
$72 \%$ of $\mathrm{D}_{\mathrm{EP} .}$ & 13.6 & 10.4 \\
\hline
\end{tabular}

Table 7. The measured earth resistance with addition of 5 Litters of the Dead Sea water, Coal and iron-filings at electrode depth of $1 \mathrm{~m}$.

\begin{tabular}{ccc}
\hline & \multicolumn{2}{c}{ Measured earth resistance $(\Omega)$} \\
\cline { 2 - 3 } Distance $\mathrm{D}_{\mathrm{CE}}$ & Single Rod & Double Rods \\
\hline $52 \%$ of $\mathrm{D}_{\mathrm{EP} .}$ & 9.6 & 7.1 \\
$62 \%$ of $\mathrm{D}_{\mathrm{EP} .}$ & 9.72 & 7.2 \\
$72 \%$ of $\mathrm{D}_{\mathrm{EP} .}$ & 9.7 & 7.0 \\
\hline
\end{tabular}

of soil treatment compared to the case without soil treatment. Furthermore, the Dead Sea water can be added to reduce the earth resistance of the ring system where very small earth resistance is needed.

\section{References}

[1] Hammuda1, A., Nouri, H. and Al-Ayoubi, M. (2011) An Investigation into Substation Grounding and Its Implementation on Gaza Substation. Energy and Power Engineering, 3, 593-599.

[2] Kinsler, M. (1998) A Damage Mechanism: Lightning-Initiated Fault-Current Area to Communication Cables Buried Beneath Overhead Electric Power Lines. IEEE Industrial and Commercial Power Systems Technical Conference, 109-118.

[3] Na, J., Kang, H., Kim, Y., Chang, K., Hwang, Y. and Ko, T. (2011) Experimental Study on the Lightning Impulse Dielectric Characteristics of Sub-Cooled Liquid Nitrogen for a High Voltage Superconducting Fault Current Limiter. IEEE Transactions on Applied Superconductivity, 21, 1336-1339. http://dx.doi.org/10.1109/TASC.2011.2105456

[4] Dusang, L.V. (2008) A Ground Fault Protection Method for Ungrounded Systems. IEEE Electric Power Conference EPEC, 1-6.

[5] Ferrell, B. and Ostdyk, R. (2010) Modeling and Performance Considerations for Automated Fault Isolation in Complex Systems. IEEE Aerospace Conference, 1-8.

[6] Kamel, R., Chaouachi, A. and Nagasaka, K. (2011) Comparison the Performances of Three Earthing Systems for Micro-Grid Protection during the Grid Connected Mode. Smart Grid and Renewable Energy, 2, 206-215. http://dx.doi.org/10.4236/sgre.2011.23024

[7] Colominas, I., Gómez-Calviño, J., Navarrina, F. and Casteleiro, M. (2001) Computer analysis of Earthing Systems in Horizontally or Vertically Layered Soils. Electric Power Systems Research, 59, 149-156. http://dx.doi.org/10.1016/S0378-7796(01)00148-1

[8] Shalash, N., Haidar, A. and Abdul Sattar, K. (2012) Grounding Locations Assessment of Practical Power System. Energy and Power Engineering, 4, 19-27. http://dx.doi.org/10.4236/epe.2012.41003

[9] Roberts, J. and Aituve, J. (2001) Review of Ground Fault Protection Methods for Grounded, Ungrounded, and Compensated Distribution Systems, SEL.

[10] Hanninen, S. (2001) Single Phase Earth Faults in High Impedance Grounded Networks Characteristics, Indication and Location. Valtion Teknillinen Tutkimuskeskus Technical Research Centre of Finland, Espoo.

[11] Kojovic, L.A., Day, T.R. and Chu, H.H. (2003) Effectiveness of Restricted Ground Fault Protection with Different Relay Types. Power Engineering Society General Meeting, IEEE, 13-17 July 2003, 1-6.

[12] Jinxi, M. and Dawalibi, F.P. (2006) Grounding Analysis of a Large Electric Power Station. IEEE International Conference on Power System Technology, Chongqing, 22-26 October 2006, 1-6.

[13] Jacob, D. and Nithiyananthan, K. (2008) Effective Methods for Power Systems Grounding. WSEAS Transactions on Business and Economics, 5, 151-160. 